\title{
Paisagem: realização da essência humana. 0 caso das Pequenas Centrais Hidrelétricas do estado de São Paulo (1890-1960)
}

Dossier Eletromemória: PAISAGEM E HistóRIA

\section{Eduardo Silva Bueno}

Mestre em Geografia Física, Universidade de São Paulo. Projeto Eletromemória ll: Eixo Temático Paisagem e

Meio Ambiente. São Paulo [SP] Brasil. <eduardo.bueno@usp.br>.

\section{Resumo}

Este estudo tem o objetivo de discutir o conceito de paisagem e posteriormente aplicá-lo à interpretação das Pequenas Centrais Hidrelétricas (PCHs) do Estado de São Paulo do período entre 1890 a 1960 abordadas pelo Projeto Eletromemória ll. Foi desenvolvido um pensamento que culmina na definição do conceito de paisagem que se apresenta como o a harmonia entre os objetos articulados por unidades espaciais. Entendeu-se que a as unidades espaciais modificam a paisagem na medida em que permitem ao homem captar a harmonia e atuar para o melhoramento de sua manifestação de forma consciente, aumentando paulatinamente sua capacidade de produzir paisagem. As PCHs foram entendidas como unidades espaciais enquanto sua infraestrutura (barragens, represas, canal de adução, conduto forçado, casa de máquinas etc.) foi analisada como os objetos que nela se articulam. Da relação entre as PCHs como articuladora dos objetos componentes de sua infraestrutura se pôde desenvolver método, técnica, prognóstico e teste que permitem realizar um estudo sob a perspectiva de como as PCHs mudam a paisagem a elas associada.

\section{Palavras-chave}

Paisagem, Pequenas Centrais Hidrelétricas (PCHs), Fenomenologia de Goethe, Antroposofia, Huberto Rohden.

\section{Landscape: accomplishment of the human essence. The case of the Small Hydropower Plants of the State of São Paulo (1890-1960)}

\begin{abstract}
This study aims to clarify the concept of landscape and later applying it to the interpretation of the Small Hydropower Plants (SHPs) of the State of São Paulo from 1890 to 1960 approached by the Electromemory ll Project. A thought was developed that results in the definition of the concept of landscape as the harmony between the objects articulated by spatial units. It was realized that the spatial units change the landscape insofar as they allow human beings to perceive the harmony and act to consciously improve its manifestation, gradually increasing its capacity to produce landscape. The SHPs were understood as spatial units while its infrastructure (dams, channel, penstock, power house etc.) was considered as the objects articulated by it. From the relation between the SHPs as articulators of the component objects of its infrastructure we developed a method, technique, prognostic and test that allow to perform a study about how the SHPs change the landscape attached to them.
\end{abstract}

\section{Keywords}

Landscape, Small Hydropower Plants (SHPs), Goethe's Phenomenology, Anthroposophy, Huberto Rohden. 


\section{Os objetos e o homem}

Marx diz que relações comerciais explicam o fato de uma cerejeira, árvore de origem biologicamente oriental, localizar-se no ocidente (BESSE, 2006a). Do mesmo modo, pode-se pensar que condições físicas e biológicas também explicam a localização da cerejeira, pois, para sobreviver, ela precisa de solos, relevo e clima minimamente adequados, assim como nutrientes vindos de materiais em decomposição, decompositores de matéria orgânica, agentes adubadores e polinizadores etc. Resumindo, a cerejeira seria explicada por um conjunto de fatores físicos, biológicos e antrópicos em interação. Essa é uma visão corrente da explicação da paisagem na ciência geográfica. Bertrand (1971) é uma referência exemplar dessa linha de pensamento quando trata do geossistema como integrador do meio físico, biológico e antrópico.

Entretanto, se a cerejeira for entendida como objeto que quer se experimentar de todas as formas possíveis para se conhecer e evoluir, a forma de raciocinar sobre a transformação muda. Segundo o pensamento de Bergson, sujeito e objeto se coincidem no plano da essência, mas são diferentes no plano da existência (ROHDEN, 2008b). Então é licito pensar que em essência, objetos e homens são uma coisa só e que neste aqueles se conscientizam a ponto de querer experimentar sua manifestação no plano objetivo, da existência.

Essa premissa nos distancia da perspectiva fenomenológica comumente trabalhada em geografia, ilustrada no pensamento de Merleau-Ponty e Éric Dardel (BESSE, 2006b) e de Péguy (BESSE 2006c). Por outro lado, nos aproxima da fenomenologia de Goethe (2012), do desenvolvimento da mesma apresentado na corrente filosófica denominada antroposofia (STEINER, 1984, 1988, 1998, 2004, 2013), e das obras de Rohden (2007, 2008a, 2008b, 2008c). Tal distinção se baseia, em linhas gerais, na idéia de que os objetos não se pensam no homem, mas despertam nele.

A cerejeira está no homem, na medida em que este toma contato com a mesma em sua manifestação objetiva, ela desperta dentro dele e quer se experimentar nele. 0 homem aprecia o sabor, cheiro, textura de seus frutos, se reconhece como árvore que faz sombra, que serve de suporte para um balanço para uma criança brincar, etc. $\mathrm{O}$ homem existe em toda a Terra, então a cerejeira quer se experimentar em todo homem, independente se do oriente ou ocidente.

As relações comerciais são condição de expansão para que a cerejeira se experimente em todos os homens do mundo. 0 solo, o clima, a água, a fauna que a mantém, são condição para que ela subsista como árvore que dá frutos, serve de balanço etc. em um pomar, praça, ou qualquer outro lugar do ocidente.

A cerejeira então precisa se espalhar pelo mundo e se manter nele para poder se experimentar no homem. Ela incita no homem relações comerciais para se espalhar pelo mundo, e assim transforma os objetos do mundo, seja ao ser plantada em uma praça ou quintal do ocidente, ou ao ter seus frutos e madeira manufaturados em uma fábrica. Para ser plantada ou manufaturada é preciso que instrumentos e máquinas sejam produzidos e manuseados, fábricas sejam construídas, processos produtivos e tecnológicos sejam desenvolvidos etc.

Para se manter, a cerejeira precisa se entender dentro do homem como árvore que dá frutos que podem ser colhidos em momento de diversão ou ser manufaturados e vendidos como alimento, que faz sombra, que deve ser preservada por sua beleza estética, ou porque atrai pássaros, purifica o ar etc. Cada forma de se manter exige um tipo de transformação dos objetos do mundo.

Na medida em que as transformações ocorrem, o homem passa a perceber mais os objetos transformados no espaço que as próprias cerejeiras. Logicamente, esses objetos transformados, como se objetivam no espaço, assim como as cerejeiras, querem se experimentar também no homem. Do mesmo modo, devem se manter, para isso devem também despertar na consciência dos homens, se entendendo neles de alguma forma. Conforme os objetos transformados se entendem na cabeça dos homens, simultaneamente eles se objetivam, gerando novas transformações, sejam de objetos já transformados ou não. Quanto mais transformações, mais distintos objetos existentes no mundo passam a ser relacionados e interpretados. 
Dessa forma, cada vez menos se percebe o objeto natural, a cerejeira, e cada vez mais se percebem as transformações de objetos que ela implicou para se espalhar e se manter e as transformações dessas próprias transformações. Distancia-se de um objeto particular e caminha-se para a transformação dos mais diversos tipos de objetos. Quanto mais transformação, mais os objetos perdem sua particularidade e mais se diluem em um corpo de objetos transformados.

Uma ilha paradisíaca, ainda não transformada pelo homem, é uma forma do conjunto de objetos que a compõe se manter, de se experimentar no homem como ilha turística, ou unidade de proteção ambiental e pesquisa e não como objetos naturais a serem experimentados de forma particular. 0 que se manifesta não são mais os objetos naturais da ilha, mas uma ilha que deve ser explorada de algum modo.

Isso acontece com todos os objetos, o que se apresenta à nossa percepção são objetos transformados que querem se experimentar gerando mais transformações, simultaneamente os mesmos são alvo de transformação para que outros objetos transformados se experimentem. Os objetos se solidarizam, são transformadores e transformados, essa harmonia é sua essência, acontece em todos e se manifesta em cada um de forma distinta.

A transformação dos objetos reflete essa harmonia de forma cada vez menos particular, por consequência, atua para permitir aos homens com alguma sensibilidade percebê-la em sua forma geral, ter consciência da mesma e ajudar os outros homens a alcançarem esse estágio de evolução. Viver o objeto não é passo único e último destino do ser humano, é o primeiro passo para a essência dos objetos tomar consciência de si nos homens.

\section{E como essa harmonia pode ser apreendida em seus aspectos gerais?}

Goethe (Figura 1) afirma que a essência das coisas se manifesta no plano do existir (BESSE, 2006d). Em botânica é o caso da planta primordial (o princípio de todas as plantas) que se manifesta na folha (STEINER, 1984) ou da harmonia entre os objetos, que se manifesta através do vapor, no caso das pinturas da paisagem (BESSE, 2006d). Cheiros, sabores, textura, forma etc., são propriedades dos objetos, assim como a cor, mas somente esta permite aos objetos experimentarem no homem a manifestação de sua essência. Tal essência, como sugere Goethe, é a luz, e a cor, para o poeta alemão, é a carne do mundo (BESSE, 2006d). A cor é que está associada diretamente à imagem que se faz do mundo, esta ocorre na mente do homem, permite a este interiorizar o mundo. Outros atributos dos objetos, para se traduzirem em imagem, de alguma forma, precisam passar pelo atributo cor.

A imagem é que permite ao homem conhecer a harmonia entre os objetos. Em Steiner (2013), apreende-se que é no confronto de imagens formadas com o maior nível de detalhe possível que surge o conhecimento das coisas. Quando uma imagem se transforma em outra é que se apreende a harmonia entre os objetos. Por isso, quanto mais os objetos são transformados e articulados, mais possibilitam ao homem comum interiorizá-los em imagens, que ao se transformarem, permitem reconhecer a harmonia entre os objetos que as constituem. Como já foi dito, o homem deve passar pela cor para formar suas imagens.

Para Goethe, cada objeto tem uma cor advinda do derramamento de luz em um meio turvo opaco (matéria) (BESSE, 2006d). Dependendo das características deste, a luz se revela em diferentes cores (BESSE, 2006d). 0 vapor é a primeira matéria turva a ser banhada de luz, a matéria mais suave, é o próprio corpo da cor cujo leve azulado tudo clareia, revelando as cores dos demais objetos dados em matéria mais turva (BESSE, 2006d).

Segundo Goethe, o vapor é o que adoça as cores vivas quando estão próximas umas às outras e também é o que permite enxergar seus contrastes entre tons frios e quentes (BESSE, 2006d). É o que suaviza a luz, o brilho das cores particulares, permite às cores deslizarem suavemente umas sobre as outras, funde o contorno dos objetos sem se apagarem (BESSE, 2006d). As Figuras 2 e 3 ilustram o vapor segundo a percepção de Goethe. 


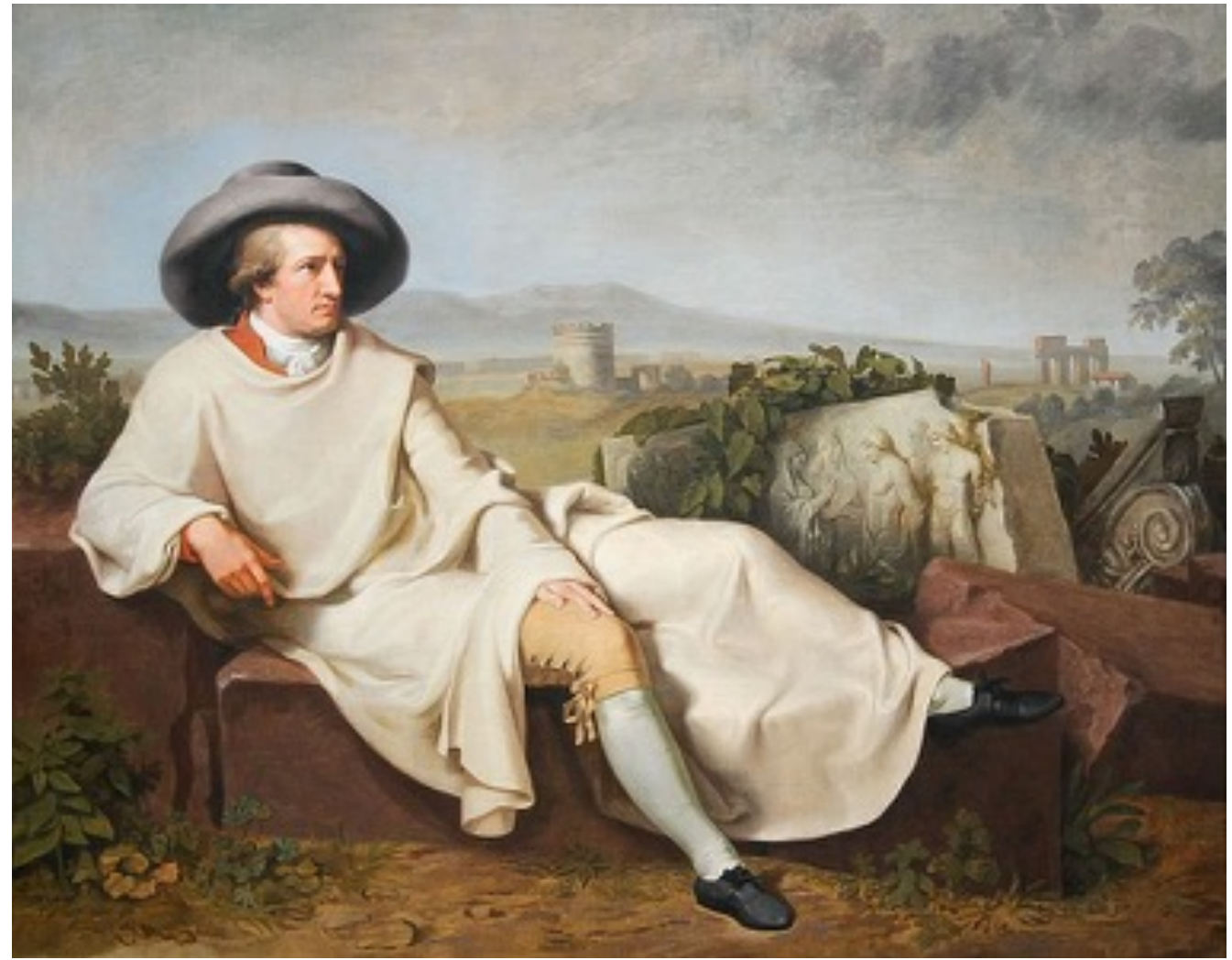

Figura 1. Poeta e pensador alemão Johann Wolfgang Von Goethe (1759-1832) retratado em 1787 por Johann Henrich Wilhelm Tischbein (1751-1829).

Fonte: http://de.wikipedia.org/wiki/Datei:Johann_Heinrich_Wilhelm_Tischbein_007.jpg

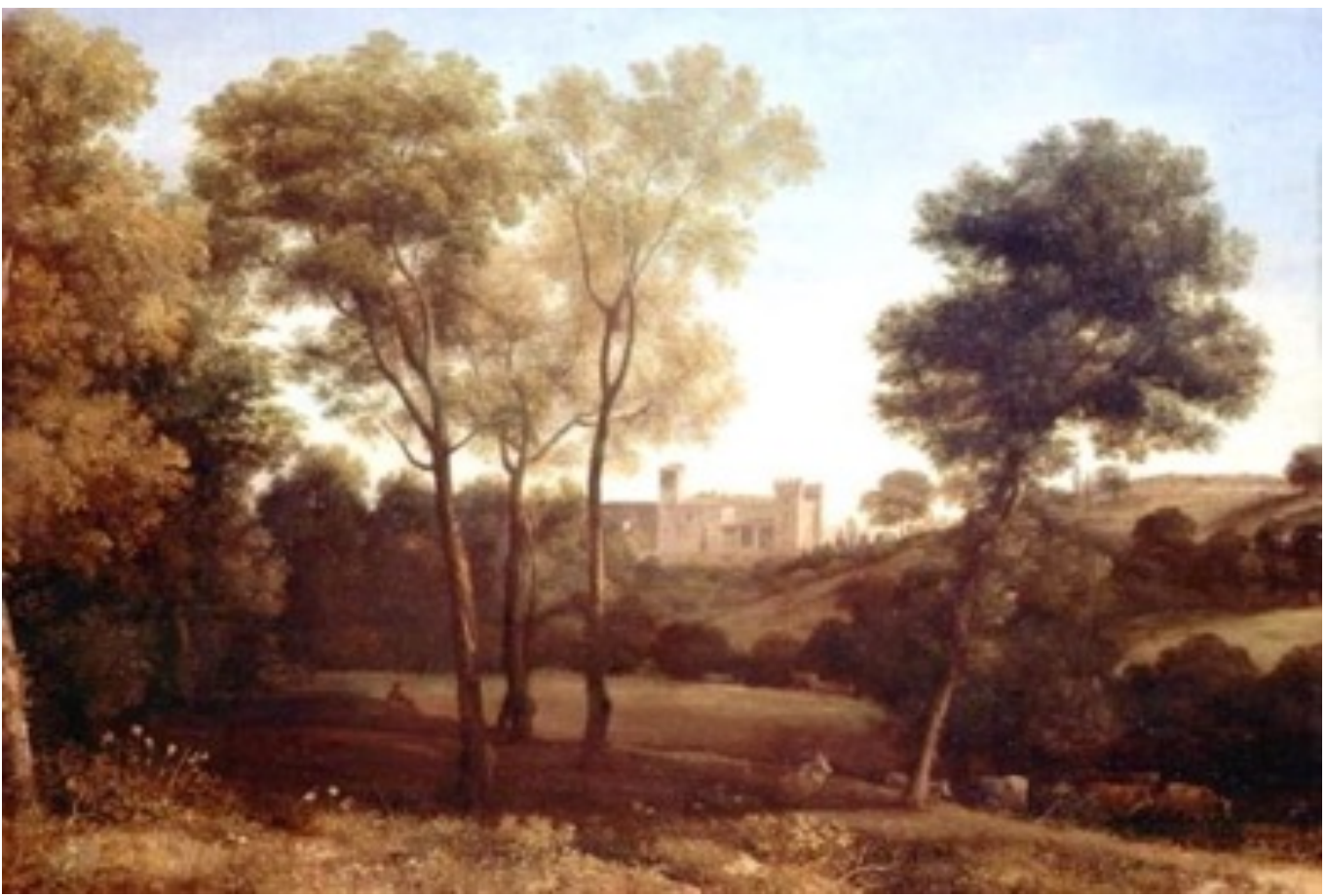

Figura 2. Paisagem com Castelo, de Claude Lorrain (1600-1682). Segundo Goethe, este pintor é o que melhor representa "[...] a harmonia vaporosa da luz [...]" (BESSE, 2006d, p. 49-50). Lorrain é o guia escolhido por Goethe na viagem à Itália a partir de Roma em direção à Sicília (BESSE, 2006d). Goethe tenta perceber e explicitar de acordo com seu pensamento o que Lorrian viu e explicitou em seus quadros, segundo Besse (2006d) o vapor que faz as cores deslizarem umas sobre as outras, funde os contornos dos objetos sem o apagarem, a harmonia entre os elementos da paisagem, a unidade da natureza, sua eterna atividade criadora.

Fonte: http://www.claudelorrain.org/Landscape-with-Castle.html

BUENO, E.S. Paisagem: realização da essência humana. O caso das Pequenas Centrais Hidrelétricas do estado de 


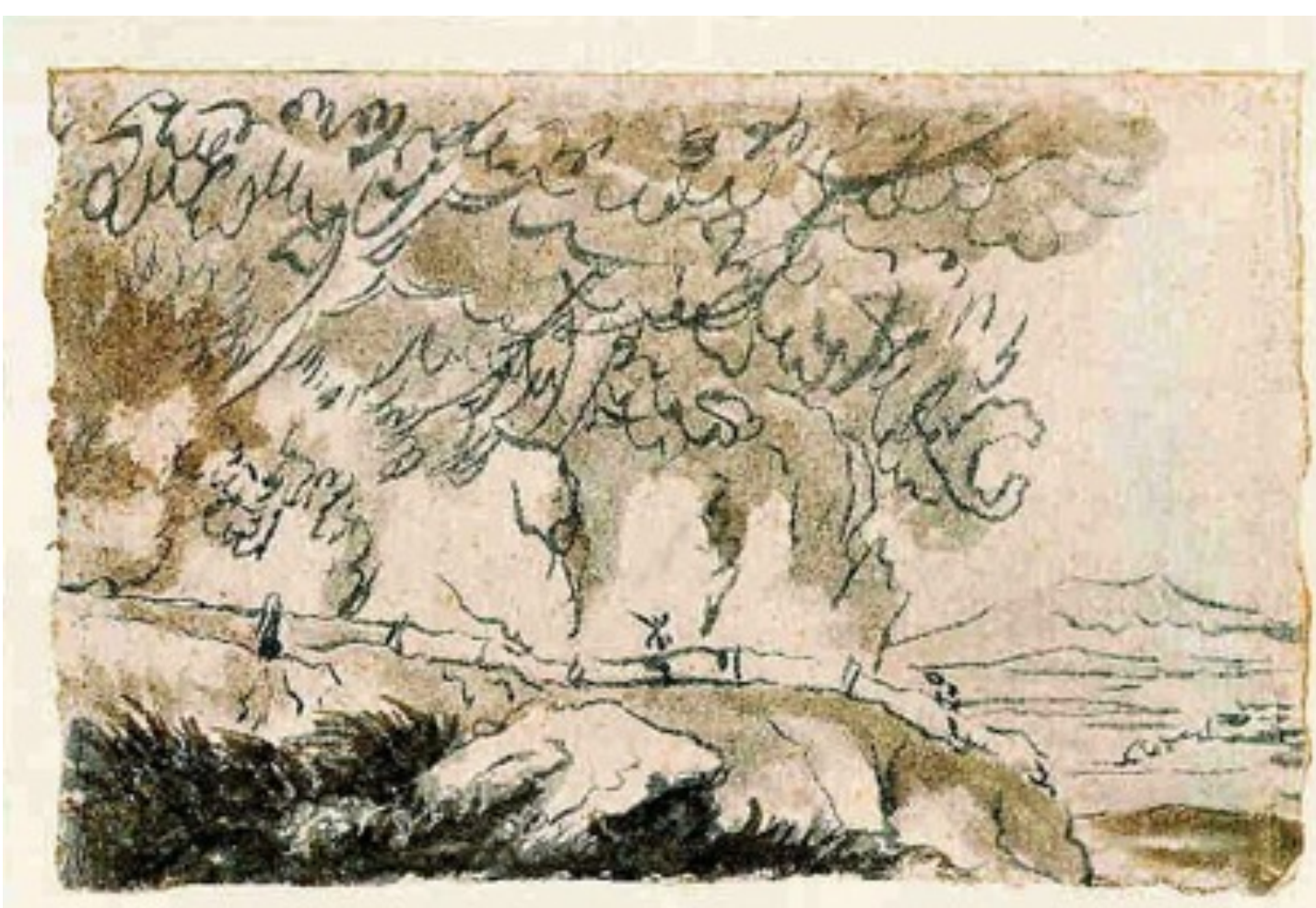

Figura 3. O Solfatara de Pozzuoli, aquarela de Goethe realizada em 1787. Solfatara é um vulcão raso antigo situado nas proximidades de Nápoles, sul da Itália. Emite gás sulfídrico (vapores de enxofre) através de fumarolas. Nesta obra específica teria o vapor do vulcão o mesmo significado que a névoa dos quadros de Lorrain tem para Goethe? Em sua aquarela Goethe expressa, de alguma forma, o que Lorrain representou na Figura 2, segundo Besse (2006d), o esfumar das demais cores nas distâncias azuladas?

Fonte: http://de.wikipedia.org/wiki/Datei:Goethe,_Die_Solfatara_von_Pozzuoli,_1787.jpg

Quanto mais os objetos transformam e são transformados, mais eles tendem a reunir diversas cores possíveis existentes no mundo numa única vista abarcada pelo olho humano. Isso porque cada vez mais diferentes tipos de objetos são envolvidos conforme se aumenta a capacidade de transformação. Ao invés de haver somente uma cerejeira silvestre em meio a uma floresta verde, tem-se uma cerejeira em uma praça, que além do verde de suas árvores, tem ao redor o cinza do asfalto, o colorido das pinturas das construções, dos carros, dos cães de rua etc.

Havendo mais cores reunidas em uma vista abarcada por um olhar, há maior possibilidade de se reconhecer as diversas cores particulares e a harmonia entre elas, o fundir dos contornos dos objetos. A harmonia entre as cores é a objetivação da essência dos objetos, do seu interminável transformar e ser transformado.

Uma lei científica, uma obra de arte, um ensinamento de um místico, uma sabedoria popular etc. são formas de manifestação da harmonia entre as cores feita pelo homem. A vontade dos objetos se experimentarem no ser humano o levará a manifestar a harmonia, o transformar e ser transformado em determinados objetos, através da escrita, fala, comportamento, produção de artefatos etc.

Quanto mais a harmonia se manifesta, mais sua manifestação é capaz de tocar os homens, inspirando-os a transformar ainda mais os objetos do mundo. Por exemplo, leis científicas aumentam a capacidade tecnológica de atuação no mundo. A transformação dos objetos generalizada através de todos os homens leva à representação da harmonia em alguns homens, e esta leva a uma maior capacidade de transformação através de todos os homens. E quanto mais transformação, mais 
representação da harmonia em alguns homens. Alguns homens precoces reconhecem a harmonia na natureza mais primeva, mas é mais fácil a maioria dos homens comuns reconhecerem a harmonia nas cidades, ambientes mais transformados.

E quanto mais um homem se comporta como cientista, artista etc., um manifestante da harmonia, mais nele desperta a consciência da harmonia que manifesta, ele percebe que é aquele algo geral o qual manifesta de forma específica através de conceitos, obras de arte etc. Na medida em que se conscientiza que é a harmonia que manifesta, enxerga a manifestação da harmonia em todos os objetos do mundo, inclusive nos outros homens. Percebe então que é tudo o que se manifesta no mundo. Passa então a utilizar seus talentos (técnicos, artísticos, científicos etc.), para ajudar outros homens a alcançarem seu estágio de evolução, a perceberem que são a manifestação do mundo individualizada em um único ser, que por isso é consciente.

O homem percebe que ele também é o transformar e ser transformado dos objetos, ele é transformado na medida em que evolui de um ser que experimenta objetos para um que manifesta sua essência, para outro que se conscientiza da essência que manifesta, para outro que se conscientiza de todas as outras formas de manifestação da essência. Também transforma na medida em que age no mundo de forma inconsciente para manter objetos, manifesta a essência destes e manifesta o seu enxergar de todas as outras formas de manifestação da essência.

Quando todos os homens chegarem a esse último estágio, os objetos estarão conscientizados em todos eles, não precisarão mais se objetivar no espaço e tempo para ajudar o homem a saber o que é. Agora estão no plano do ser individualizado e plenamente conscientizado e, em teoria, podem se manifestar de outras formas acima de espaço e tempo para outros fins.

Se a essência do homem é a essência de tudo individualizada, ao homem que se conscientiza da mesma só resta o amor. Ele ama tudo que se manifesta, pois sua essência conscientizada é a essência objetivada que manifesta aqueles. A essência do homem é o criador dos objetos conscientizada em um único indivíduo, ao homem só resta o amor do criador pela criatura. Esse amor é aquele definido por Albert Schweitzer, que Huberto Rohden comumente cita em suas obras, como "a mais pura razão".

Se o homem amar os objetos do reino mineral, orgânico e também os outros homens, não haverá poluição da água, ar, solo, desrespeito aos seres vivos e aos direitos humanos, guerras etc. Estes só existem porque o homem não tem plena consciência do que é, e são condição para levar o homem a saber o que ele é, sustentam a contínua transformação dos objetos. Por exemplo, uma represa poluída que pertence a um manancial fornecedor de água a um grande aglomerado urbano existe porque sustenta tal aglomerado, auge da transformação de objetos que deveria permitir ver a harmonização das diversas cores do mundo em único golpe de vista.

Cabe aos homens comuns, ainda pouco conscientes do que realmente são, que nos dias atuais vivem em sua maioria em ambientes muito transformados, os urbanos, continuar seu processo de evolução, tentando reconhecer a harmonia entre os objetos dispostos à sua frente e consequentemente manifestá-la, contribuindo assim para o desenvolvimento da humanidade também.

Quanto mais os homens forem capazes de reconhecer a harmonia nos ambientes modificados, menos danos cometerão com a natureza objetiva e consigo mesmos. A represa antes poluída para sustentar a aglomeração urbana não será despoluída porque sua poluição é muito custosa ou porque despoluída traz de volta a fauna local, por exemplo, mas porque a essência dos objetos que a constituem é totalmente consciente no homem. Neste a essência conscientizada dos objetos reconhece sua manifestação ainda inadequada no plano objetivo e atua para que a mesma se torne adequada.

Nos próximos tópicos esta filosofia será melhor esclarecida e se demonstrará como pode ser aplicada ao estudo das PCHs abordadas pelo Projeto Eletromemória ll. 


\section{Paisagem}

Para Goethe a paisagem é como um vapor que harmoniza os objetos porque os percebe em uma representação pictórica, a pintura. É o leve azulado que harmoniza as cores dos objetos. Neste trabalho, assim como os objetos particulares são associados à cor, o vapor é associado às unidades espaciais.

A unidade espacial é o corpo da própria cor, é a primeira matéria que se turva, que permite ver as cores dos objetos e as harmoniza. É o objeto que primeiro manifesta sua essência, o transformar e ser transformado, é invisível, mas perceptível assim como o vapor, é o que permite ver os objetos mais densos que ali atuarão transformando e sendo transformados de maneiras particulares. Permite enxergar o transformador e o transformado que se manifestam de diferentes formas em cada objeto.

Ao mesmo tempo é o particular mais geral, por isso possui corpo invisível, que esfuma os limites dos objetos, permitindo ver sua harmonia.

A unidade espacial é a essência dos objetos presente no homem que se exterioriza no plano da existência, encontrando seu reflexo no mundo. Como saiu do próprio homem, é mais desenvolvida, é menos inconsciente que aquela dos objetos, por isso é invisível, sua manifestação é mais sutil, não é palpável, nem possui contorno como os objetos, tem o poder de articular estes para que em conjunto permitam ao homem perceber sua harmonia. Assim como os objetos despertam dentro do homem e se reconhecem no mundo naquele, o mesmo ocorre com a unidade espacial, ela reconhece no mundo aquilo que a objetiva, podendo articular objetos que em conjunto manifestam no plano do visível o que é no plano do invisível.

São as unidades espaciais mundo afora que instigam a cerejeira a se distribuir pelo mundo, elas são a base segura que a cerejeira citada por Marx necessita para se distribuir e poder se experimentar no homem, pois são a extensão objetiva deste. Se os objetos estão no homem de forma individualizada e conscientizada, eles tendem a ir em direção ao homem, para se unificarem com seu ser, se conhecerem, para isso precisam de um objeto superior, que faça parte do objetivado, mas tenha contato direto com o homem, a essência individualizada, esse intermediário é a unidade espacial.

A cerejeira adequará sua experimentação no homem segundo as diretrizes da unidade espacial que a articula com outros objetos.

Bueno (2014) mostra que as unidades de proteção ambiental da Região Metropolitana de São Paulo são a exteriorização de algo invisível: o fato da área urbana corresponder às áreas abaixo de $800 \mathrm{~m}$ de altitude e as áreas naturais àquelas situadas acima de $800 \mathrm{~m}$, independente de seu tamanho ou localização dentro ou fora da mancha urbana da metrópole paulista. Os objetos transformadores e transformados que se manifestam em cada unidade de proteção ambiental atuam de forma particular para traduzir no plano do visível aquilo que as unidades exteriorizam no plano do invisível.

A Paisagem é a unidade espacial harmonizando os objetos que se apresentam à nossa vista. 0 homem está na raiz desse processo, participa da paisagem de forma inicialmente inconsciente e deve tomar consciência da mesma de forma paulatina. Entretanto, o homem só terá captado plenamente a paisagem se for capaz de atuar no mundo de acordo com a harmonia que captou. Assim contribuirá para que toda a humanidade evolua e ao mesmo tempo estará apto para evoluir, prosseguir em etapas evolutivas superiores.

Há portanto na ação humana pelo menos duas formas de atuação.

Na primeira, na medida em que o homem reconhece a harmonia entre os objetos articulados por sua essência exteriorizada, a unidade espacial, ele a manifesta de alguma forma (obra de arte, lei 
científica etc.). Essa manifestação consiste numa pintura, música, experimento científico, instrumento tecnológico, sabedoria popular transmitida de forma oral etc. Tal criação humana despertará um maior nível de conscientização humana que encontrará seu reflexo, manifestação, objetivação no mundo, surgindo uma nova unidade espacial.

Uma nova unidade espacial, ao surgir, contribui para que mais objetos sejam transformados de forma intensa, contribuindo para a percepção da harmonia entre eles pelo homem. Na medida em que capta a harmonia e a manifesta em determinadas criações pelo mundo, o mesmo tomará consciência de que é a harmonia que ele próprio manifesta.

O reconhecimento da essência despertada em maior nível no homem se dá em um conjunto de objetos primários, sejam eles transformados ou não pelo ser humano, e que a manifesta no plano objetivo sem consciência. Entretanto, esse seu corpo é invisível, não tem limites definidos nem é palpável como um objeto concreto. Um sítio não é palpável, o que é palpável são os objetos que o constituem (vegetação natural e plantações, animais criados, casas, paiol, cerca etc.). Quanto mais a essência despertada no homem em determinado nível através de uma criação humana se reconhece no plano objetivo através de objetos primários, mais articulará vários objetos secundários para que se manifeste de forma mais refinada no plano do visível, permitindo ao homem reconhecer a harmonia entre tais objetos secundários.

Se o homem reconhece o invisível através do visível, reconhecerá a essência que há nos dois. Só ultrapassando a manifestação invisível mais sutil da essência é que o homem reconhecerá esta. Por isso deve percebê-la na harmonia entre objetos articulados. Esse processo, para se manter, precisa se desdobrar em outra forma de atuação.

A segunda forma de atuação se baseia no fato de que o homem, para se conscientizar, precisa apreender a harmonia no plano do visível, desse modo a unidade espacial é o primeiro passo para que isso aconteça. Na medida em que o homem habita a Terra, de forma inconsciente ele cria unidades espaciais sem ainda concretizá-las. Assim como ele não tem consciência da essência dentro dele, também não tem consciência de sua exteriorização. Conforme concretiza sua essência exteriorizada de forma cada vez menos inconsciente, mais tem condições de reconhecê-la articulando objetos e mais pode participar dessa articulação de forma consciente, melhorando-a.

Assim, atua no sentido de contribuir para a manutenção e eficácia de um conjunto de objetos transformados que sustentam outros conjuntos transformados advindos da primeira forma de atuação, ou seja, da objetivação da essência humana despertada em novo grau a partir da introspecção de uma criação sua. Essa segunda atuação não só sustenta o resultado da primeira, como vem dela também. A unidade espacial que aborda, bem como os objetos que articula, são resultado também da objetivação da essência humana despertada em novo grau a partir da introspecção de uma criação humana.

Na medida em que atua na aplicação da harmonia que reconhece também tomará consciência de que é a harmonia que manifesta.

É nesta segunda atuação que se pode falar de mudança da paisagem a partir da unidade espacial. A articulação entre os objetos realizada pela unidade espacial de forma inconsciente permite ao homem fazer paisagem, reconhecer a harmonia de forma gradativa. Então, este atua no mundo com o intuito de melhorar a aplicação da harmonia, dispondo os objetos de forma que a unidade espacial articule melhor aqueles que precisam ser melhor articulados ou integre à articulação aqueles ainda não articulados. A melhor e maior articulação permite a transformação mais intensa dos objetos, que permite uma forma de captação da harmonia (paisagem) mais completa, que será novamente aplicada aos objetos. Assim aumenta a capacidade do homem de produzir a paisagem.

Uma das perspectivas do geógrafo é descrever essa segunda forma de atuação se fazendo no mundo e contribuir para que sua realização ocorra de forma mais cada vez melhor. 


\section{PCHs}

A tecnologia de associar a força do movimento das águas para girar uma turbina geradora de eletricidade é uma criação humana. Tal criação despertou no homem uma forma mais evoluída de consciência de sua essência que, sendo assim, precisa se manifestar. Essa forma mais evoluída será denominada de potencial hidráulico e encontra no mundo sua objetivação inconsciente. Essa objetivação são as corredeiras de um curso d'água, elas representam de forma visual o movimento das águas, bem como sua força. 0 desnível entre a parte mais alta e baixa da queda d'água permite que a força da mesma, energia potencial (gravitacional), seja representada por seu movimento rápido, percebido pela espuma branca, barulho da corredeira, velocidade das águas etc.

Mas a queda d'água, a cachoeira, a corredeira, não são palpáveis, não têm limites, como os objetos. Não se pode pegá-las, nem delimitá-las. Não são visíveis, visíveis são os objetos primários que as constituem, as rochas e as águas que por elas caem. Quando a essência despertada do homem reconhece sua objetivação na queda d'água, surge a unidade espacial Pequena Central Hidrelétrica $(\mathrm{PCH})$.

É a PCH, como unidade espacial, que vai articular os objetos secundários do mundo para manifestar o que é de forma visível. A barragem, o canal de adução, a tubulação forçada, a casa de máquinas, as casas do administrador, dos funcionários etc., são os objetos secundários visíveis articulados pela PCH invisível. Tais objetos transformadores e transformados se experimentam no homem de forma particular segundo a regência da $\mathrm{PCH}$. A PCH é percebida na medida em que tais objetos a compõem.

É preciso reconhecer a PCH em cada visão que se tem do conjunto de objetos da mesma. Os objetos da PCH se apresentam de maneira distinta à nossa vista, mas sua harmonia, sua articulação pelo invisível, a PCH, é a mesma.

Para aplicar tal método é preciso de uma técnica, esta consiste em obter mapas que caracterizem os objetos primários das quedas d'água (suas rochas em diferentes alturas). Basicamente tais representações são ou advêm das cartas topográficas e mapas geológicos das quedas d'água e arredores. Seriam muito importantes as cartas, mapas e plantas específicos produzidos na construção das PCHs. Deles se extrairiam intervalos de altitude e tipos de rocha das quedas. Em cada vista da PCH, ilustrada por fotos devidamente produzidas, se poderá reconhecer os intervalos de altitude e tipos de rochas observados nos mapas.

Primeiramente se escolheriam pontos altos ou outros que permitiriam ver grande quantidade de objetos secundários da PCH. Através de mapas e de entrevistas com funcionários da PCH se tentaria identificar pontos de referências localizados próximos ao limite institucional da mesma. $\mathrm{Na}$ extremidade das fotos deveriam aparecer tais pontos de referência, permitindo que seu conteúdo se refira ao máximo de objetos secundários possíveis contidos em seu ângulo de visada.

O ângulo de visada seria obtido, através de uma bússola, a partir da medição do azimute (ângulo entre a linha de visada entre o observador e ponto de referência e o norte magnético). Nos mapas, a linha do norte é uma só, cruzando-se as linhas de visada no ponto em que a foto foi retirada se obtém o ângulo de visada.

Após a identificação da localização do observador no mapa através das coordenadas obtidas em campo por meio de um GPS, tal ângulo seria sobreposto aos mapas, dando idéia dos intervalos de altitude e tipos de rocha ali existentes. Estes se manifestam na foto através da vegetação e solos evidenciados em determinados tipos de rochas, de campos, áreas gramadas e abertas, bem como de condutos forçados que ilustram a declividade local etc. Dessa forma, imagens de satélite e fotografias aéreas da área institucional da PCH e arredores também consistem em instrumentos importantes a serem utilizados no estudo. 
Fazendo isso para todas as PCHs se tentará observar um padrão, ou seja, intervalos de altitude e tipos de rocha presentes nas fotos da PCH ainda em funcionamento, ou seja, as repotencializadas ou originais, operando com o único intuito de produzir energia elétrica.

Esse padrão refletiria a harmonia entre os objetos secundários das PCHs, sempre que olhados em conjunto, se poderia perceber tal padrão.

Mas por que tal harmonia só seria reconhecida nas PCHs citadas acima e não nas abandonadas ou que até produzem energia, mas tem outras funções, como museu e parque, mesmo que aparentemente em situação precária?

Nem todas as quedas d'água refletem de forma objetiva no mundo o potencial hidráulico das águas para movimentar uma turbina geradora de eletricidade. 0 homem aprende errando. Para encontrar as quedas d'água corretas, passa por outras não adequadas. Na medida em que os insucessos ocorrem, outras quedas d'água adequadas são encontradas.

Inicialmente, o homem aborda as quedas d'água mais convenientes, mais próximas, localizadas em sua propriedade ou em propriedade de baixo custo de aquisição etc. Entretanto, algumas não refletem o potencial hidráulico associado às quedas d'água de forma conceitual. Tal potencial reconhece sua objetividade no conceito de queda d'água e não em qualquer queda d'água. Se tal conceito existe é porque as quedas d'água adequadas que o objetivam existem, mas isso não significa que todas as quedas d'água são adequadas.

Desse modo, a unidade espacial não surge nas quedas d'água não adequadas e, por consequência, a articulação entre os objetos secundários que permitirão captar a harmonia entre os mesmos também não ocorrerá. Os objetos atuarão de forma independente, não harmônica, seu transformar se sobreporá ao ser transformado, pois o seu transformado depende da harmonia com os outros objetos (deixar-se transformar para transformar). Sua intenção agora só é transformar para se experimentar no homem, não quer ser transformado.

Os objetos tendem a entrar em algum nível de colapso, não poderão se sustentar sem sua essência, no ímpeto de se transformar, um prejudicará o outro. Esse seria o caso das PCHs abandonadas. Seus objetos secundários, a casa de máquinas, a barragem, o canal de adução, os condutos forçados etc., entrariam em colapso porque a queda d'água ali existente não objetiva o potencial hidráulico associado às quedas d'água como conceito; ali nunca houve nem haverá uma unidade espacial $\mathrm{PCH}$, pois, para esta surgir, é preciso que o potencial hidráulico encontre seu reflexo em determinada queda d'água adequada à sua objetivação no mundo. A queda d'água ainda permanece lá. Talvez, em determinado momento, alguns homens movidos somente por seus interesses queiram reativar a PCH que lá ocorrera. Tal atividade tenderia ao fracasso, em algum momento os objetos da pretensa PCH entrariam em algum nível de colapso.

Questões econômicas, como mudanças de comportamento do mercado cada vez mais global e integrado, são umas das condições para que tal colapso ocorra, assim como o comércio é condição para que a cerejeira de Marx ocorra no ocidente. A PCH renderia lucro ao seu proprietário se fosse verdadeira, pois sempre haveria mercado para a energia que produz. Como seus objetos não estão em harmonia, a produção de energia elétrica é prejudicada e os custos para sua produção ficam cada vez mais dispendiosos. A atividade do mercado só levará ao momento em que tais custos serão insustentáveis. Falta de incentivo estatal, baixa do preço da energia, maior concorrência de outras PCHs ou de demais formas de produção de energia, queda do consumo de energia etc., são condições para deixar insustentável a produção de energia já insuficiente por natureza.

Energia elétrica sempre terá mercado, sempre terá consumidor, pois o papel das PCHs é sustentar centros urbanos, e é nestes que os objetos transformados e transformadores atuam cada vez mais articulados por unidades espaciais de forma concentrada. Na cidade é que é mais fácil para a maioria dos homens comuns perceberem a harmonia entre os objetos, reconhecer a essência e manifestá-la de alguma forma. Para isso, é preciso que esses homens controlem e 
superem seu ego paulatinamente, ver a essência depende deles mesmos e não mais do ambiente, este, na cidade, implora para que sua harmonia seja reconhecida. Controlar e superar o ego é procurar ver a essência das coisas em cada manifestação do mundo e não se restringir somente à sua manifestação, sua superficialidade, que o cotidiano de cada pessoa impõe.

Quanto às PCHs que possuem museus, a queda d'água também não objetiva totalmente o potencial hidráulico. Os objetos não se colapsam porque algo os harmoniza, mas este algo não é uma unidade espacial PCH, mas outro tipo de unidade espacial, como um parque, por exemplo. A inserção da palavra Parque no nome de uma PCH é uma evidência disso, como no caso da UsinaParque do Corumbataí em Rio Claro. Nesta $\mathrm{PCH}$, a casa do administrador possui beleza destacada, sua suntuosidade evidencia que ali não ocorre uma $\mathrm{PCH}$, mas um parque/museu. A tendência é que a geração elétrica nesta usina, com o tempo, se torne secundária e até mesmo seja paralisada, e todos os seus objetos (infraestrutura) sejam harmonizados pela verdadeira unidade espacial que ali ocorre. Seu museu, atualmente com ares de abandono, deve ser bem utilizado e revitalizado no futuro, conforme se toma consciência de que a unidade espacial que harmoniza os objetos da PCH na realidade não é uma $\mathrm{PCH}$, isso já começou, na medida em que o museu foi implantado e a PCH já é denominada institucionalmente de Usina-Parque. A queda d'água foi apenas condição para que uma outra criação humana ao se interiorizar no homem se reconhecesse em outros objetos primários da área em que ocorre, fazendo surgir a verdadeira unidade espacial que ali vigora. A articulação entre os objetos da PCH pela unidade espacial verdadeira apenas concretiza tal fato. A unidade espacial museu/parque sempre existiu na PCH Corumbataí, o funcionamento da PCH até os dias atuais é uma condição para que objetos secundários se articulem cada vez mais segundo a unidade espacial museu/parque.

Alguma criação humana encontrou sua objetividade onde se encontra a PCH Corumbataí. Essa objetividade não está na queda d'água, mas em determinados objetos primários naturais ou artificiais que se manifestam na beleza de seus objetos secundários, como a casa do administrador e a chaminé próxima à casa de maquinas. Tal beleza não seria necessária se o intuito da pretensa PCH fosse somente produzir energia elétrica. Se deveria pensar e demonstrar isso antes de se transformar uma PCH em museu e ou parque ou qualquer outra coisa, para não se desperdiçar dinheiro público em algo com tendência ao fracasso. Se a queda d'água objetiva o potencial hidráulico, não se deve transformá-la em museu, parque etc., deve se buscar evidências que indiquem que a queda d'água não é adequada e que é condição para a existência de outra unidade espacial que se manifesta visivelmente através de objetos secundários (infraestrutura) favoráveis ao estabelecimento de um museu, parque etc.

No caso da Usina-Parque de Corumbataí, uma unidade espacial que de PCH passa a um parque e ou museu também cumpre seu papel como sustentadora do ambiente urbano, na medida em que informa ao público, principalmente citadino, a história da PCH que ali ocorre ou ocorrera, como sua energia, além de sustentar, participou do processo de urbanização do Estado de São Paulo e a importância de se preservar ambientes naturais locais para a sobrevivência e sustentação de gerações futuras. Como se sabe que as gerações futuras tendem a habitar as cidades, a preservação da natureza cabe no sentido de sustentar essas populações, o foco continua a ser o urbano. 0 museu-parque parece ter mais apelo, ser mais interessante ao público urbano que rural. Este, por exemplo, mesmo utilizando energia elétrica cotidianamente, não é tão ligado à mesma como as populações urbanas, além disso, está acostumado com ambientes mais naturais, assim como aqueles situados nos arredores da PCH. Um indício disso é que foi observado que a maioria das PCHs percorridas realizam visitas para escolas situadas em cidades próximas.

Consequentemente, as PCHs cujo potencial hidráulico é objetivado por quedas d'água adequadas são as que fornecem energia elétrica à rede integrada de energia que perpassa o Estado de São Paulo. Qualquer modificação prevista para elas deve respeitar seu papel: fornecer energia elétrica a centros urbanos.

Tais PCHs ainda não articulam totalmente os objetos para que o homem perceba a harmonia entre eles, pois ainda há desarmonia entre os mesmos, a poluição dos reservatórios de algumas

BUENO, E.S. Paisagem: realização da essência humana. O caso das Pequenas Centrais Hidrelétricas do estado de 
PCHs ilustra isso. Mas esse desequilíbrio não é suficiente para desativar a PCH como aconteceu na PCH Cariobinha, em Americana, pois sua queda d'água objetiva o potencial hidráulico associado às quedas d'água em geral. A tendência é que nas PCHs, problemas de poluição de reservatórios, vandalismo, pesca ilegal etc., sejam solucionados ao longo do tempo. A transição de PCH antiga para uma repotencializada mostra que a harmonização está acontecendo, a poluição de suas águas, por exemplo, indica que ela irá continuar.

Reconhecendo a harmonia entre os objetos destas PCHs, segundo o método e técnica propostos, se reconheceriam os objetos primários das quedas d'água (topográficos, litológicos etc.), bem como os objetos secundários (infraestrutua da usina) que se articulam na medida em que manifestam de forma apurada o que os objetos primários manifestam de forma primária, a unidade espacial PCH. Então, se poderia imaginar o que poderia ser feito para que a harmonia entre os objetos atingisse também aqueles objetos ainda não harmonizados, como as águas poluídas observadas nas barragens. Analogamente, como dispor os objetos secundários para que sejam articulados pela unidade espacial PCH.

Desse modo, se contribuiria para que os objetos da PCH se articulassem cada vez mais por aquilo que mais cedo ou mais tarde vai lhes articular, facilitando a percepção de sua harmonia pelos homens nas PCHs. E principalmente, se contribuiria para que a PCH atuasse de forma cada vez mais eficiente para aquilo que deve fazer, ou seja, sustentar centros urbanos para os quais é enviada a energia da rede em que está conectada.

É assim que se entenderá como as PCHs paulistas, datadas do período entre 1890 a 1960 , modificaram a paisagem. Este estudo participará da modificação dessa paisagem, pois contribuirá para a apreensão dos objetos das usinas sendo articulados pela unidade espacial PCH dada em qualquer vista que se tem da mesma, findando em uma atitude, o como melhorar a articulação entre os objetos pela própria PCH. Isso aumenta a capacidade de apreensão dos objetos articulados, aumentando a capacidade de se fazer paisagem nas PCHs.

Se a paisagem se restringe ao captar a harmonia entre os objetos articulados pela unidade espacial, não é paisagem, pois para ser paisagem, precisa necessariamente resultar em uma atuação no mundo.

Se resulta em uma atuação, pode ser realizada em qualquer parte do mundo. Dessa forma, o que se percebe nas PCHs é uma forma do mundo se realizar assim como se realiza em qualquer outro lugar. Na medida em que reconhece a harmonia através deste estudo proposto para determinadas PCHs paulistas em demais unidades espaciais do mundo, o homem tomaria consciência de que é esta harmonia que reconhece na relação das unidades espaciais com os objetos que articula. Tal estudo é uma forma de manifestação dessa harmonia para as PCHs estudadas, e pode representar um ponto de partida para chegar a verdades mais profundas para quem quiser aplicá-lo em demais realidades.

Por fim, este estudo, se realizado, deve ser testado da seguinte forma: a harmonia percebida segundo o método e técnicas propostos nas PCHs em uso não pode ser encontrada nas PCHs abandonadas, museu-parque, ou com outro de tipo de função institucional além da produção de energia elétrica. Deve ser demonstrado que uma pretensa harmonia identificada nestas últimas não implica em uma ação nos objetos, a fim de que se melhore sua articulação pela unidade espacial PCH, não podendo, consequentemente, se obter melhor apreensão de sua harmonia, ou seja, melhor capacidade de fazer paisagem, como ocorre nas PCHs repotencializadas.

\section{Considerações finais}

Este texto visou mostrar, através das PCHs paulistas do período de 1890 a 1960, aquilo que se pode fazer em qualquer parte do mundo, ou seja, que o homem pode produzir paisagem, enxergar as unidades espaciais articulando os objetos nela contidos e que se apresentam à sua vista. Na medida em que faz isso, tem certeza de quais são as verdadeiras unidades espaciais, como atuam e como pode melhorar sua atuação, contribuindo para a sustentação de ambiente 
cada vez mais propício à percepção da essência das coisas pela maioria dos homens comuns, ambientes com maior densidade de unidades espaciais e objetos transformadores e transformados articulados pelas mesmas.

Tais ambientes imploram para ter sua harmonia percebida e despertada dentro do homem; basta este se concentrar o suficiente para percebê-la. Este estudo é ao mesmo tempo um tipo de esforço de concentração e uma pequena forma de descrição da realidade que ajuda quem quer se concentrar na busca da verdade.

\section{Agradecimentos}

À Profa. Dra. Sueli Angelo Furlan, coordenadora do Eixo Temático Paisagem e Meio Ambiente, pela apresentação do Projeto Eletromemória ll e convite para participar do mesmo. Ao Prof. Dr. Gildo Magalhães dos Santos Filho, pesquisador responsável do Projeto Eletromemória ll, que permitiu a participação do autor em tal Projeto, inclusive nas Expedições realizadas em determinadas PCHs paulistas. Também se agradece a ambos professores a revisão criteriosa e construtiva deste artigo.

\section{Referências}

BERTRAND, G. Paisagem e geografia física global: esboço metodológico. Tradução de Olga Cruz. Caderno de Ciências da Terra, Instituto de Geografia da Universidade de São Paulo, São Paulo, n. 13, p. 1-27, 1971.

BESSE, J. M. A Fisionomia da Paisagem, de Alexander von Humboldt a Paul Vidal de La Blache. In: Ver a Terra: seis ensaios sobre a paisagem e a geografia. Tradução: Vladimir Bartalini. São Paulo: Perspectiva, 2006a. p. 61-74.

Entre Geografia e Paisagem, a Fenomenologia. In: Ver a Terra: seis ensaios sobre a paisagem e a geografia. Tradução: Vladimir Bartalini. São Paulo: Perspectiva, 2006b. p. 75-95.

Nas Dobras do Mundo. Paisagem e Filosofia Segundo Péguy. In: Ver a Terra: seis ensaios sobre a paisagem e a geografia. Tradução: Vladimir Bartalini. São Paulo: Perspectiva, 2006c. p. 97-108.

Vapores no Céu. A Paisagem Italiana na Viagem de Goethe. In: Ver a Terra: seis ensaios sobre a paisagem e a geografia. Tradução: Vladimir Bartalini. São Paulo: Perspectiva, 2006d. p. 43-60.

BUENO, E. S. A área urbana e as áreas naturais da Região Metropolitana de São Paulo: de compartimentos fisiográficos a categorias geográficas. 2014. 316 p. Dissertação (Mestrado em Geografia Física) - Faculdade de Filosofia Letras e Ciências Humanas, Universidade de São Paulo, São Paulo, 2013. Disponível em: <http://www.teses.usp.br/teses/disponiveis/8/8135/tde-24022014-113819/pt-br.php>. Acesso em: 10 jan. 2015.

GOETHE, J. W. Ensaios científicos: uma metodologia para o estudo da natureza (coletânea). Apresentação e introdução: Antonio José Marques. Seleção e tradução dos textos de Goethe: Jacira Cardoso. São Paulo: Barany Editora / Ad Verbum Editorial, 2012.116 p.

ROHDEN, H. Filosofia da arte: a metafísica da verdade revelada na estética da beleza. São Paulo: Martin Claret, 2008. $127 \mathrm{p}$.

O Espírito da Filosofia Oriental: o drama milenar do homem em busca da verdade integral. São Paulo: Martin Claret, 2008a. 140 p.

Filosofia Contemporânea: o drama milenar do homem em busca da verdade integral. São Paulo: Martin Claret, 2008b. 186 p.

o Pensamento Filosófico da Antiguidade: o drama milenar do homem em busca da verdade integral. São Paulo: Martin Claret, 2008c. 222 p. 
STEINER, R. A educação prática do pensamento: aprender a pensar com base na realidade. Tradução: Octavio Inglez de Souza. 6a ed. São Paulo: Editora Antroposófica, 2013.

A filosofia da liberdade: elementos de uma cosmovisão moderna. Tradução: Alcides Grandisoli. 2a ed. São Paulo: Editora Antroposófica, 1988. 151 p.

A obra científica de Goethe. Tradução: Rudolf Lanz. São Paulo: Editora Antroposófica, 1984. 204 p.

Arte e estética segundo Goethe: Goethe como inaugurador de uma estética nova. Tradução: Marcelo da Veiga Greuel. 2a ed. São Paulo: Editora Antroposófica, 1998. 38 p.

0 método cognitivo de Goethe: linhas básicas para uma gnosiologia da cosmovisão goethiana. Tradução: Bruno Callegaro, Jacira Cardoso. 2a ed. São Paulo: Editora Antroposófica, 2004. 113 p. 